\title{
Development in building fire detection and evacuation system-a comprehensive review
}

\author{
Gajanand S. Birajdar', Rajesh Singh², Anita Gehlot ${ }^{3}$, Amit Kumar Thakur ${ }^{4}$ \\ ${ }^{1,2,3}$ Department of Electronics Engineering, Lovely Professional University, India \\ ${ }^{4}$ Department of Mechanical Engineering, Lovely Professional University, India
}

\begin{tabular}{|c|c|}
\hline Article Info & ABSTRACT \\
\hline & Fire is both beneficial to man and his environment as well as destructive and \\
\hline ReceivedFeb27, 2020 & but once it crops up its consequences will be devastating. The early detection \\
\hline Revised Jun6, 2020 & of fire will help to avoid further consequences and saves the life of people. \\
\hline Accepted Jun 18, 2020 & $\begin{array}{l}\text { During the fire accidents, it is also important to guide people within } \\
\text { the building to exit safely. Because of this, the paper gives a review of }\end{array}$ \\
\hline Keywords: & $\begin{array}{l}\text { literature related to recent advancements in building fire detection and } \\
\text { emergency evacuation system. It is intended to provide details about fire }\end{array}$ \\
\hline $\begin{array}{l}\text { Fire detection } \\
\text { IoT }\end{array}$ & $\begin{array}{l}\text { simulation tools with features, suitable hardware, communication methods, } \\
\text { and effective user interface. }\end{array}$ \\
\hline
\end{tabular}

LoRa

Safe evacuation

Smart fire detection

Copyright (C) 2020Institute of Advanced Engineering and Science. All rights reserved.

\section{Corresponding Author:}

Amit Kumar Thakur,

Department of Mechanical Engineering,

Lovely Professional University,

Jalandhar - Delhi G.T. Road, Phagwara, Punjab, 144411-India.

Email: amitthakur3177@gmail.com

\section{INTRODUCTION}

With the rapid growth in population, buildings are also growing vertically due to the shortage of occupancies. However, with these buildings growing vertically, there arise problems regarding the safe evacuation of people during an emergency like a fire. Similarly, with the growth of insulating materials which catch fire easily and their excessive use in building, a threat to the life of building and human is also increasing. Many people are killed every year, and more are hospitalized due to the fire in India. An average of 520 injuries and 40 deaths occurs per year according to the data provided by NFPA.

A fire Accident occurs very rarely, but once it occurs it's consequences will be devastating. As a result, there is substantial attention given by researchers worldwide for the development of intelligent building systems. Many of these casualties can be avoided if we detect a fire early and guide people to a safe location. To build a suitable fire detection and safe evacuation system it is necessary to focus on parameters such as appropriate sensors, software and hardware tools, and combination techniques and at the end effective user interface.

This article gives systematic reviews of intelligent fire detection and evacuation system as a combination of fire detection (sensors, technology), evacuation assistance (Static/Dynamic Display) and crowd monitoring and prediction (Video, non-video, GPS, Bluetooth). Besides, the review is evaluated based on (i) fire and building simulation software, (ii) suitable hardware (with their merits and demerits), (iii) fire and smoke detecting sensors, (iv) communication methods and (v) effective user interface for a safe exit. In this, efforts have been taken to identify research gaps, and suggestions are made to fulfill the need. Further, a novel architecture is recommended for future fire detection and safe evacuation system. 


\section{LITERATURE SURVEY}

Early detection of fires is important to save the life of human beings as well as property. In this case, multiple sensors need to be installed at different places of the building which plays a crucial role [1]. A system based on LabVIEW is proposed to detect and alert fire events in [2]. A portable community video surveillance system developed in [3] can be used to detect people's motion. Environmental parameters such as temperature, the concentration of toxic gases are measured and monitored in [4] using NodeMCU and sensors. In [5], Low-cost IoT based evacuation Service is implemented for real-life situations of Building Automation System (BAS) applications.The Mobile terminal-based system is discussed in [6][8] which provides a 3D interactive model of building and guide evacuees to exit safely. In [9], the author proposed an FPGA based fire warning and multi-door control system which provides the information onthe floor where the fire occurred. The integration of IoT with WSN would be effective for fire detection and alerting application [10]. RFID devices and wireless sensors have been used to detect environmental conditions and image identification techniques and digital signage are used to guide people through a safe route [11][13]. To enhance evacuation, plan a Situation-Aware System is used in which end-user specific business rules were created that practically helps actions concerning evacuation plans [14].

Building Information Modeling (BIM) tools can be used to create a virtual environment for fire emergency evacuation [15], [16]. A rescue operation during fire emergency can be fastened using cloudbased Rescue Worker Interface (RWI) which assists rescue warden by proving real-time information of building fire, the flow of fire, people density, and position of remaining warden [17][18]. In [19], the author proposed a system which formulates real-time evacuation path based on real-time data acquisition and calculations of risk distributions. In case of fire events system provides directional guidance concerning the time and location of fire accidents [20]. GIS and IoT technology is used to obtain information about the building. Further, the evacuation path has been estimated using Matlab [21]. ZigBee based fire alarming and prevention system is proposed in[22].In [23], a motion detection sensor based person detection technique is discussed for IoT based fire evacuation assisting system. A sudden change in the motion of an individual in-crowd is detected by the optical flow model [24]. Indoor navigation and evacuation can be improved using a mobile terminal based app like EasyGo [25]. To deal with outdoor evacuation UAV is preferred [26]. LoRa, which is low power and long-range communication technology, is introduced in [27]. In [30], the author suggested a system with a mesh network of fire sensor, and path planning strategy which detects fire event alerts about an emergency to occupants and fire services. A detailed comparison table is being depicted in Table1.

Table1. Comparison of hardware, fire sensing devices, simulation software, communication technology and user interface used by various researchers

\begin{tabular}{|c|c|c|c|c|c|}
\hline Source & Hardware/Technology & FireSensing Devices & Simulation Software & $\begin{array}{l}\text { Communication } \\
\text { Technology }\end{array}$ & User Interface \\
\hline [1] & Raspberry Pi & $\begin{array}{l}\text { LM 35Smoke } \\
\text { SensorGas Sensor } \\
\text { (MQ9) }\end{array}$ & FDS & GSM & $\begin{array}{l}\text { No work on } \\
\text { evacuation }\end{array}$ \\
\hline [3] & $\begin{array}{l}\text { nRF24L01 transceivers, } \\
\text { Laptopwith Arduino }\end{array}$ & IR Flame Sensor & $\begin{array}{l}\text { PythonMATLAB's } \\
\text { roboticsPackage }\end{array}$ & $\mathrm{RF}$ transceivers & $\begin{array}{l}\text { HTML/CSS based } \\
\text { website }\end{array}$ \\
\hline [5] & Ardunio & $\begin{array}{l}\text { RFM23B RFID, } \\
\text { LM35, HC-05,PIR } \\
\text { Sensor }\end{array}$ & BIM & Bluetooth & $\begin{array}{l}\text { Audio Signal, SMS } \\
\text { on user mobile. }\end{array}$ \\
\hline [4] & $\begin{array}{l}\text { Mobile Phone with } \\
\text { RFIDReader capability }\end{array}$ & RFID tags & $\begin{array}{l}\text { Path Planner, } \\
\text { Viewpoint Calculator, } \\
\text { and MobiX3D }\end{array}$ & $\begin{array}{l}\text { RFID } \\
\text { technology }\end{array}$ & $\begin{array}{l}\text { Mobile phone- } \\
\text { based App }\end{array}$ \\
\hline [7] & $\begin{array}{l}\text { Mobile Phone with } \\
\text { NFC and RFID reader }\end{array}$ & $\begin{array}{l}\text { Active temperature and } \\
\text { RFID sensor tags }\end{array}$ & $\begin{array}{l}\text { MobiX3D, Viewpoint } \\
\text { Calculator }\end{array}$ & $\begin{array}{l}\text { RFID, Cloud } \\
\text { Computing }\end{array}$ & Mobile Phone \\
\hline [9] & FPGA, Microcontroller & Temperature Sensor & TimeNET & $\begin{array}{l}\text { Wireless } \\
\text { Transceiver }\end{array}$ & $\begin{array}{l}\text { Direct Alarm } \\
\text { System is provided } \\
\text { at each floor }\end{array}$ \\
\hline [12] & Zigbee, RFID & $\begin{array}{l}\text { Temperature, } \\
\text { Humidity, and Light }\end{array}$ & MySQL Database & $\begin{array}{l}\text { WSN } \\
\text { Technology }\end{array}$ & LCD Display \\
\hline [17] & Microcontroller & Smoke & $\begin{array}{l}\text { BAS(Building } \\
\text { Automation System) }\end{array}$ & Cloud & App on Smartphone \\
\hline [21] & IoT, Arduino & $\begin{array}{l}\text { LM35, HC-05, PIR } \\
\text { Sensor }\end{array}$ & BIM & $\begin{array}{l}\text { Bluetooth, RF } \\
\text { Communication }\end{array}$ & $\begin{array}{l}\text { Audio Signal, SMS } \\
\text { on user mobile. }\end{array}$ \\
\hline [31] & $\begin{array}{l}\text { Turtlebot2, Parrot AR. } \\
\text { Drone 2.0\& DJI } \\
\text { Phantom } 4\end{array}$ & $\begin{array}{l}\text { Illuminance sensor, } \\
\text { Arduino Uno as a } \\
\text { sensor }\end{array}$ & Google Map & Wireless & Application Mobile \\
\hline [50] & IoT, Microcontroller & $\begin{array}{l}\text { Temperature, CO, } \\
\text { OpticalDensity Sensor }\end{array}$ & GIS, Matlab & $\begin{array}{l}\text { wireless sensor } \\
\text { Network }\end{array}$ & $\begin{array}{l}\text { Fire Alarm, } \\
\text { Emergency } \\
\text { Lightening system }\end{array}$ \\
\hline
\end{tabular}




\section{DEVELOPMENT IN FIRE DETECTION AND EMERGENCY EVACUATION}

\subsection{Fire sensing, sensors and devices}

It involves a Multi-sensor module for sensing parameters like heat, smoke, flame, gas etc.as depicted in Figure 1, with signal conditioning, amplifier circuit, processing unit, alarm system, and safe evacuation path display [33].

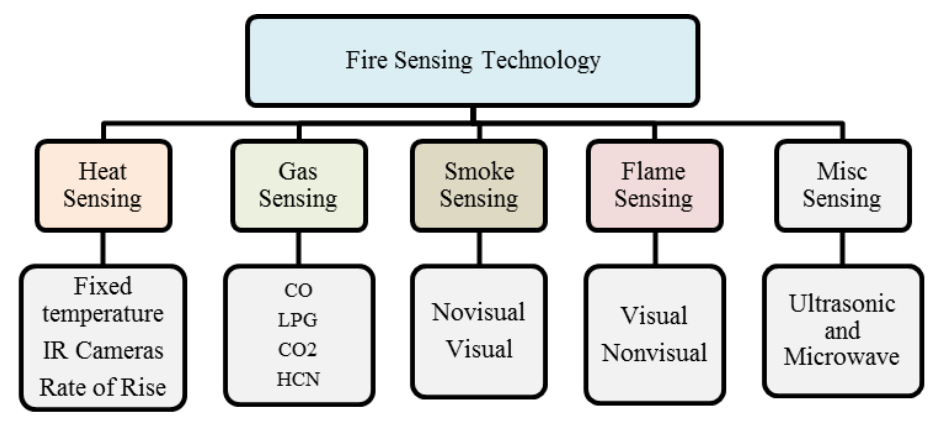

Figure 1. Fire sensing technologies[31]

\subsection{Hardware platforms}

After detecting a fire event it needs to be processed for further course of actions, for which effective hardware platform plays a key role. Figure 2 shows the block diagram of the fire alarm system. Many hardware devices are used by researchers till now, the details are given below:

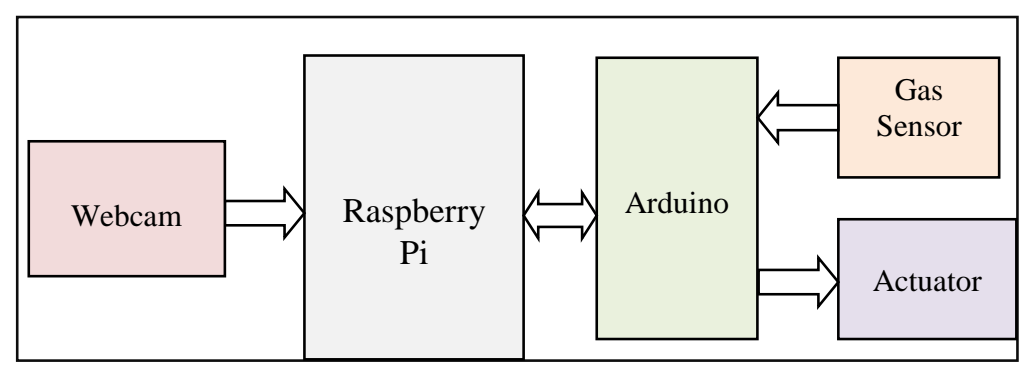

Figure 2. Block diagram fire alarm system [34]

\subsubsection{Raspberry pi}

It is cheaper and minicomputer that can easily plug into a monitor. Connecting the internet to Raspberry pi is very easy as it is having an Ethernet port and USB Wi-Fi dongles. Multiprocessing is possible using this board. Programming languages like Python, C, C++, and Ruby can be used.It is a low-cost computer based on Linux OS, featured with an Ethernet controller and two USB ports. It is having ARM-architecture, with $512 \mathrm{MB}$ data memory, onboard graphics processing unit (Videocore IV). It supports multiple programming languages and software installation. We can install Apache HTTP Webserver to serve the webpage.

\subsubsection{Arduino board}

Arduino boards are equipped with many digital inputs and output pins that can be interfaced with different expansion boards or shields and other required circuits. These boards featured with serial communications interfaces such as USB, which are also used for loading programs from personal computers. These boards can be programmed using programming languages such as $\mathrm{C}$ and $\mathrm{C}++$.

\subsubsection{FPGA}

The Filed Programming Gate Arrays (FPGA) are semiconductor-baseddevices equipped with interconnection circuits and programmable logic blocks. The FPGA provides features such as the high speed with real-time processing. It can be programmed to meet the requirement of functionality even after its 
manufacturing. The emergency evacuation system for multi-storey buildings using FPGA is proposed which can operate at the very clocking rate and can handle multiple inputs and multiple outputs simultaneously. This feature of FPGA's is very useful when there is multi-storey building as it needs many sensors and local control boards for every floor.

\subsubsection{DSP}

DSP is a kind of processor for processing real-time signals. During fire accidents, fire signals need to be processed in real-time with high precision and high speed. DSP not only controls the sampling procedure but deals with the sampling data in advance also.Table 2 provides the comparison of all hardware platforms used which readily displays the response time with the kind of language supported, thus highlighting that FGPA and DSP have faster response time as compared with Raspberry Pi and Arduino board.

Table 2. Comparison of hardware platform

\begin{tabular}{|c|c|c|c|c|c|c|}
\hline Hardware & Response time & Language Supported & Cost & $\begin{array}{l}\text { Onboard } \\
\text { Storage }\end{array}$ & $\begin{array}{c}\text { Multi } \\
\text { Programming }\end{array}$ & $\begin{array}{c}\mathrm{I} / \mathrm{Os} \\
\text { (Approx.) }\end{array}$ \\
\hline Arduino Board & Comparatively Slow & $\mathrm{C} / \mathrm{C}++$ & Low Cost & Available & Not Possible & 13 \\
\hline Raspberry Pi & Faster than Arduino & $\mathrm{C}, \mathrm{C}++$, Python, ruby & Expensive & Need SD Card & Possible & 40 \\
\hline DSP & $\begin{array}{l}\text { Fast real-time } \\
\text { computation }\end{array}$ & $\begin{array}{c}\mathrm{C}++, \mathrm{C}, \mathrm{JAVA}, \\
\text { JavaScript, LLVM bit } \\
\text { code }\end{array}$ & Expensive & $\begin{array}{l}\text { Need External } \\
\text { Memory }\end{array}$ & Possible & 110 \\
\hline
\end{tabular}

\subsection{Simulation tools}

\subsubsection{BIM}

Building Information Modeling (BIM) provides the facility to makea layout in three-dimension (3D) and carry out disaster prevention activities. Specifically, it is used in the design of fire sprinklers and an alarming system. e.g. BIM 360, AutoCAD, Revit, etc. A 3-dimensional building evacuation and guidance system overcomes the problem of poor visibility in 2 dimensional based systems. The basic use of BIM technology is the exchanging and processing of building information, so the architecture of the fire evacuation system can be designed. BIM-based 3-dimensional model is very close to a real-time scenario and it is proven that this model helps to provide information such as rescue conditions, evacuation paths, etc[35].

\subsubsection{GIS}

Spatial or geographical information can be achieved through a software tool such as a geographic information system (GIS)[36]. It contains activities such as capture, store, manipulate, analyzes, manage, and present. GIS and CAD integration helps to visualize geospatial information from various locations of the building during a fire emergency.The GIS is used to simulate evacuation environment and to visualize evacuation process. In [37], the author presented a multi-agent-based fire evacuation model, in which GIS is used to capture the geospatial data of agents and trace its location and provide a safe exit path.

\subsubsection{FDS}

Fire Dynamics Simulator (FDS) is a fire-driven fluid flow model with computational fluid dynamics. It is a sort of a simulation tool developed by NIST's Building Fire Research Laboratory. FDS can analyze three-dimensional fires very quickly [38]. This enables simulation of smoke and heat transfer from fire, besides, FDS provides a fire detector and water sprinkler analysis.PyroSim is a kind of simulation tool can be used as a Fire Dynamic Simulator (FDS). It can also be used to simulate the motion of people.

\subsubsection{MATLAB}

MATLAB based image processing can be used to detect a fire accident. Any CCTV camera mounted in the building premises will take the input image for the device from video in real-time. Initially, we need to separate the fire and background from the received image using the color segmentation method. Further, fire growth is estimated by comparing two consecutive fire images. If fire growth continues over certain images, the emergency alarm is switched on and the computer screen displays the real-time video with the fire indication in red color.MATLAB robotics package has been used to perform path planning. MATLAB AHP toolbox can be used to calculate available evacuation paths and avoid high-risk ones based on the information of the properties, people density, and evacuation distance. Figure 3 displays color segmentation with a five frame difference in the image processing methodology adopted for fire detection based on MATLAB. Detail comparison of software tools is mentioned in Table 3. 


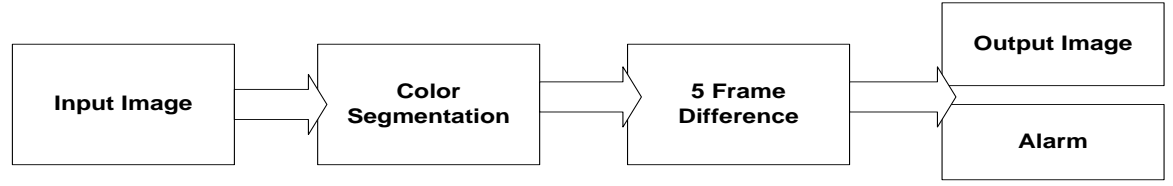

Figure 3. MATLAB based image processing for fire detection [31]

Table 3. Comparison of simulation tools used to design smart fire detection and safe evacuation system

\begin{tabular}{ccc}
\hline Source & Software Tool & Use cases in Fire safety \\
\hline$[7]$ & Mobix3D & To show a 3D view of the exit path \\
{$[19]$} & CAD & 3D Floor design \\
{$[29]$} & FDS & To determine the flow of fire \\
{$[34]$} & BIM & 3D dimensional building visualization \\
{$[37]$} & GIS & For designing routing service \\
{$[31]$} & MATLAB & Image processing for fire detection \\
\hline
\end{tabular}

\subsection{Communication technology}

Sensors are the end devices that are meant to collect various environmental parameters for early detection of fire. These sensors are connected in a suitable type of network for smooth communication among them. Following are the communication technology preferred by researchers:

\subsubsection{Zigbee}

It is a wireless communication technology based on IEEE 802.15.4, used for remote low-power digital radios and automation. It is used for various applications like monitoring hydrant, fire alarming system, predicting safe exit path, etc., in fire detection and safe evacuation system. The physical range of ZigBee wireless communication is about 10 to 20 meters and it varies according to environmental conditions. Figure 4 displays the flow diagram of a wireless sensor network. It uses small and low powered radio devices and it consumes less amount of power to transmit and receive data.

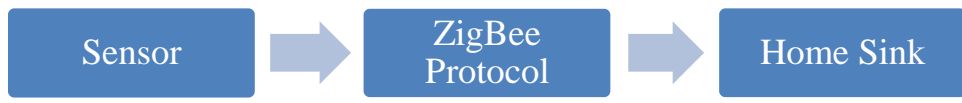

Figure 4. Flow diagram of wireless sensor network

\subsubsection{RFID}

Radio-Frequency Identification tag (RFID) uses radio waves to read and collect tag information attached to any object. It can detect and read from several feet of distance and it not needs to be within LoS. In many research works RFID tags are used to find the accurate evacuation path and in some cases, it is used to know the density of people in a particular region. The RFID-based module used to calculate the density of individuals in each room and to predict an algorithm-based evacuation path. This RFID reader receives signals from all tags and decides where each tag is located using a unique number.

\subsubsection{Bluetooth}

Bluetooth is a wireless technology used for the exchange of data between fixed and mobile devices for short-range communication. It's very suitable for IoT-based applications because it's power-efficient and low cost.It is preferred where distance is not a matter like within a room, communication between sensor nodes. A detailed comparison is mentioned in Table 4.

Table 4. Comparison of communication technology used in fire detection

\begin{tabular}{|c|c|c|c|c|}
\hline Hardware & ZigBee & RFID & Bluetooth & WiFi \\
\hline IEEE Spec. & 802.15 .4 & -- & 802.15 .1 & $802.11 \mathrm{a} / \mathrm{b} / \mathrm{g}$ \\
\hline Frequency (MHz) & $868-868.2$ & $433,860-960$ & $2402-2482$ & $2400-2500$ \\
\hline Range (m) & $100+$ & Upto 100 & 10 & $10-100$ \\
\hline Data Speed & $250 \mathrm{Kbps}$ & $640 \mathrm{kbps}$ & $1 \mathrm{Mbps}$ & $54 \mathrm{Mbps}$ \\
\hline Network Topology & Mesh & Point-to-Point & Point-to-Point & Star \\
\hline Security & $\begin{array}{l}\text { Highly secure 128-bit AES- } \\
\text { based encryption system }\end{array}$ & Hardware and Protocol Level & Protocol Level & WPA, WEP, etc. \\
\hline
\end{tabular}

Int J Elec \& Comp Eng, Vol. 10, No. 6, December 2020 : 6644 - 6654 


\subsection{User interface}

When fire accidents happen, people stuck inside the building should be evacuated through a path, and information ona safe evacuation route needs to be conveyed properly. Following are the available options for guiding people about safe exit path.

\subsubsection{Mobile terminal with app and/or web browser}

Withthe rapid evolution in the mobile manufacturing industry, Smartphone is easily available at a decent price. In general, each person carries his/her own Smartphone. We can develop mobile phone-based apps and/web app which can alert individuals during an emergency and also guide them by proving safe exit paths. The mobile-based app can provide a 3D view of the evacuation path using tools such as MobiX3D viewer. According to some researchers, based on the number of smartphones carrying by peoples in a geographical area it is also possible to predict the density of people in that area.

\subsubsection{Digital signage and audio visualization}

Digital signage is placed on the walls of the building, which provides information related to the environment[39]. During an emergency, these modules receive an emergency signal from the controlling unit. Along with digital signage, audio signals assist people to exit safely with proper guidance.

\section{RESEARCH GAP AND SUGGESTIONS}

\subsection{Long range communication technology}

Connected devices have so far running on traditional protocols like Bluetooth, Wi-Fi, and Cellular Network, etc. But embedded sensors and other IoT devices have different network requirements like low power, long-range, etc. The basic architecture of LoRa can be seen in Figure 5. To meet these requirements one can go for LPWAN, LoRa. LoRa is a Long Range, low power wireless, low data rate communication protocol built to construct an IoT network [40]40[41]. LoRa uses sub-gigahertz radio frequency bands which are license-free. It provides long-range transmissions $(1-15 \mathrm{~km})$ with low power consumption.

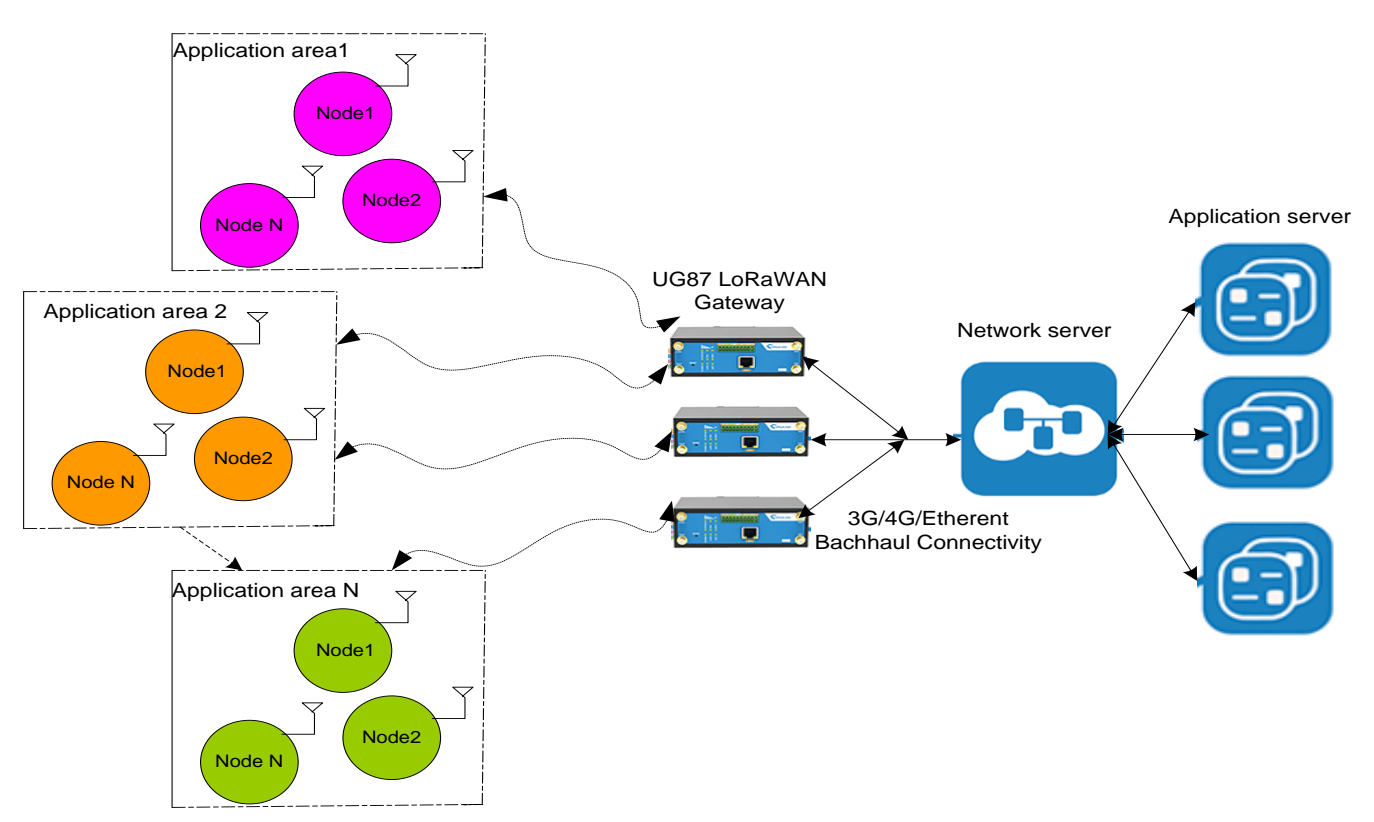

Figure 5. The architecture of LoRa

\subsection{Intelligent digital display}

During fire accidents, people caught inside building needs to be evacuated through a safe exit path. Traditional fire exit paths may lead to the wrong destination as fire spreads in any direction. Hence, the intelligent digital display needs to be developed which can guide people based on real-time situations. Figure 6 displays the sign conventions for the intelligent and dynamic LED display for right and left turn with no and safe entry [42]2, [43]. 


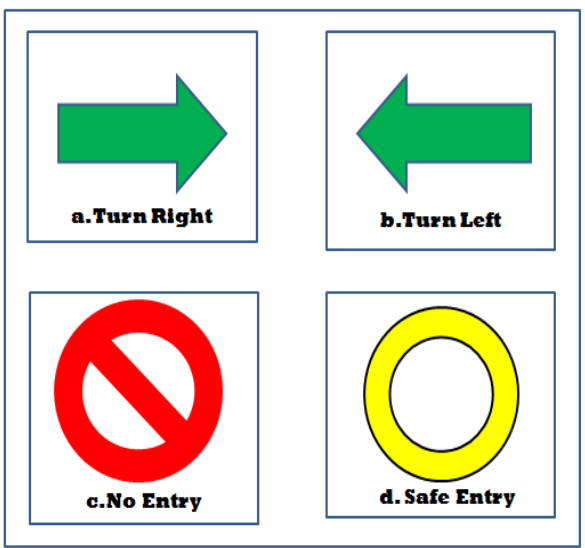

Figure 6. Intelligent and dynamic LED display

\subsection{Hardware selection \& customization}

The selection of hardware is a key parameter while designing fire detection and evacuation system. The parameters like accuracy, quick response, cost, size, robustness, and reliability need to be considered while selecting hardware [44]. Instead of considering ready boards for the designing system, it is recommended to develop customized hardware that assists to reduce cost and size. Also, it provides more scalability for future expansion.

\subsection{Density of people}

Secure evacuation of people from the building is of utmost importance during a fire emergency. People density is a key parameter in rescue operation during a fire event and it is partially addressed till now[45]5[46]. We need to install an effective system that can measure several persons stuck in a fire. Motion sensors, RFID, IP Based camera, etc, are the solution for measuring people's density.

\section{NOVEL ARCHITECTURE FOR FIRE DETECTION AND EVACUATION}

Early detection of fire helps to reduce major casualties and saves the life of human beings and property. In the view of this general architecture of smart fire detection and evacuation system is suggested in Figure 7. It is constituted by end devices, Controlling unit, Central Controlling Unit, and End-user Interface. Popular communication technologies such as Bluetooth, wifi, LoRA, etc. are used in the proposed system.

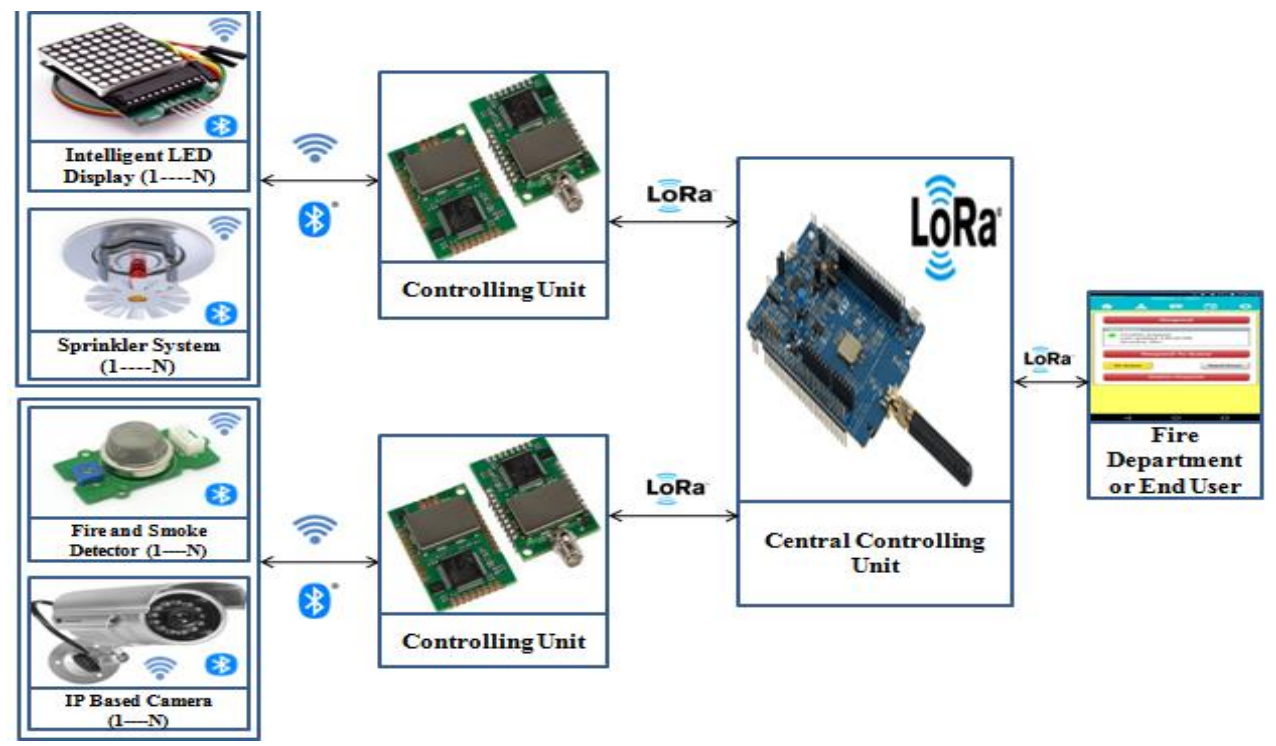

Figure 7. A novel architecture for fire detection and evacuation system 


\subsection{End devices}

The key component of our system is end devices, which play the role of collecting valuable data. The collected data like temperature, humidity can be used to decide the fire accident and take further action. These end devices involve sensors such as temperature sensor, smoke sensor, humidity sensors, actuators such as sprinkler system for controlling fire, IP based CCTV for finding the flow of fire and detecting number people inside the building and led display for guiding people to safe exit [47]7[48].

\subsection{Controlling unit}

These devices are controlling the end devices through Wi-Fi and or Bluetooth. They are capable to collect data from sensors and cameras and further based on programming it will actuate the sprinkler system and LED display accordingly. The controlling unit can be of any microcontroller/Microprocessor-based system such as Arduino, Raspberry Pi, ESP8266, etc. It is enabled with a wireless protocol such as ZigBee [49].

\subsection{Central controlling unit}

It acts as a mediator between the controlling unit and the end-user application. In this case, to communicate with end-user such a fire department we need long-range communication technology. LoRa is a long-range communication technology that contains Long Range communication capability hardware.

\subsection{End-user interface}

End-user such people inside the building should know the status of fire accidents on their mobile phones. It is possible through a mobile-based Android app [32]. It is also necessary to inform the authorized fire department regarding fire accident with live status and location. Mobile or desktop-based applications will act as a user interface for the evacuee and fire department [50].

\section{CONCLUSION}

With the rapid growth in technology, the life of human beings is changing enormously as things are becoming smarter. In the era of modern technology and lifestyle, we should think about human safety and security in an emergency condition. Fire accident is one of the dangerous events which need to be addressed effectively with the help smart technology. Because of this, we have surveyed the available methods and systems for fire detection and evacuation systems. Detail analysis is done according to parameters such as sensors, hardware platforms, software tools, and user interface for safe exit during an emergency.

We have identified some areas where still improvement is possible, and it can be done with advanced methods such as (i) LoRa for long-range communication, (ii) customized hardware for more reliability,(iii) Dynamic display guide, and (iv)people density for safe evacuation are suggested. To overcome the issues with the existing system we have proposed a novel architecture for smart fire detection and evacuation. The proposed architecture involves accurate and early sensing of a fire event, IP cameras for tracing people inside building under fire, LoRa for long communication, Zigbee for inter-node communication, actuators to enable sprinkler system and effective user interface.

\section{REFERENCES}

[1] F. Saeed, et al., "IoT-Based intelligent modeling of the smart home environment for fire prevention and safety," Journal of Sensor and Actuator Networks, vol. 7, no. 1, pp. 11, 2018.

[2] F. Idris, et al., "Intelligent fire detection and alert system using LabVIEW," International Journal of Electrical and Computer Engineering (IJECE), vol. 9, no. 3, pp. 1842-1849, 2019.

[3] S. Fakhar A. G, et al., "Development of a portable community video surveillance system," International Journal of Electrical and Computer Engineering (IJECE), vol. 9, no. 3, pp. 1814-1821, 2019.

[4] A. A. Jaber, et al., "Internet of things based industrial environment monitoring and control: a design approach," International Journal of Electrical and Computer Engineering (IJECE), vol. 9, no. 6, pp. 4657-4667, 2019.

[5] S. Gokceli, et al., "IoT in Action: Design and Implementation of a Building Evacuation Service," Journal of Computer Networks and Communications, vol. 2017, pp. 1-13, 2017.

[6] L. Chittaro and D. Nadalutti, "A mobile RFID-based system for supporting the evacuation of buildings," International Workshop on Mobile Information Technology for Emergency Response, pp. 22-31, 2009.

[7] L. Chu and S. J. Wu, "An Integrated Building Fire Evacuation System with RFID and Cloud Computing," 2011 Seventh International Conference on Intelligent Information Hiding and Multimedia Signal Processing, pp. 17-20, 2011.

[8] A. Fujihara and H. Miwa, "Disaster evacuation guidance using opportunistic communication: The potential for opportunity-based service," Big Data and Internet of Things: A Roadmap for Smart Environments, pp. 425-446, 2014. 
[9] A. S. Angel and R. Jayaparvathy, "Design and implementation of an intelligent emergency evacuation system," 6th International Conference on Computation of Power, Energy Information and Communication(ICCPEIC 2017), pp. 13-17, 2017.

[10] V. Reddy and Gayathri P., "Integration of internet of things with wireless sensor network," International Journal of Electrical and Computer Engineering (IJECE), vol. 9, no. 1, pp. 439-444, 2019.

[11] K. M. Yu, et al., "Intelligent evacuation system integrated with image recognition technology," 2015 8th International Conference on Ubi-Media Computing (UMEDIA 2015), pp. 23-28, 2015.

[12] H. P. Hsu, et al., "Emergency evacuation base on intelligent digital signage systems," 2014 7th International Conference on Ubi-Media Computng and Workshop (U-MEDIA 2014), pp. 243-247, 2014.

[13] S. Moulik, et al., "Smart-evac: Big data-based decision making for emergency evacuation," IEEE Cloud Computing, vol. 2, no. 3, pp. 58-65, 2015.

[14] A. Morales, et al., "Enhancing Evacuation Plans with a Situation Awareness System Based on End-User Knowledge Provision," Sensor, vol. 14, no. 6, pp. 11153-11178, 2014.

[15] B. Wang, et al., "BIM Based Virtual Environment for Fire Emergency Evacuation," The Scientific World Journal, vol. 2014, pp. 1-22, 2014.

[16] R. Ranjan, "Guest Editors' Introduction: Cloud-Based Smart Evacuation Systems for Emergency Management," IEEE Cloud Computing, vol. 1, no. 4, pp. 26-29, 2014.

[17] H. M. Poy and B. Duffy, "A Cloud-Enabled Building and Fire Emergency Evacuation Application," IEEE Cloud Computing, vol. 1, no. 4, pp. 40-49, 2014.

[18] X. Xu, et al., "CLOTHO: A Large-Scale Internet of Things-Based Crowd Evacuation Planning System for Disaster Management," IEEE Internet of Things Journal, vol. 5, no. 5, pp. 3559-3568, 2018.

[19] Z. Han, et al., "Investigation on an Integrated Evacuation Route Planning Method Based on Real-Time Data Acquisition for High-Rise Building Fire," IEEE Transactions on Intelligent Transportation Systems, vol. 14, no. 2, pp. 782-795, 2013

[20] C. S. Ryu, "Iot-based intelligent for fire emergency response systems," International Journal of Smart Home, vol. 9, no. 3, pp. 161-168, 2015.

[21] S. J. Liu and G. Q. Zhu, "The application of GIS and IoT technology on building fire evacuation," Procedia Engineering, vol. 71, pp. 577-582, 2014.

[22] Y. Guan, et al., "Fire Risk Assessment and Daily Maintenance Management of Cultural Relic Building Based on ZigBee Technology," Procedia Engineering, vol. 211, pp. 192-198, 2018.

[23] P. Annadata, et al., "Person detection techniques for an IoT based emergency evacuation assistance system," Adjunct Proceedings of the 13th International Conference on Mobile and Ubiquitous Systems: Computing Networking and Services, pp. 77-82, 2016.

[24] Shreedarshan K. and S. S. Selvi, "Crowd recognition system based on optical flow along with SVM classifier," International Journal of Electrical and Computer Engineering (IJECE), vol. 9, no. 4, pp. 2451-2459, 2019.

[25] L. W. Chen and J. X. Liu, "EasyGO: A Rapid Indoor Navigation and Evacuation System Using Smartphones through the Internet of Things Technologies," Proceedings of the 24th Annual International Conference on Mobile Computing and Networking, pp. 835-837, 2018.

[26] A. Sethi, "Systems and methods for outdoor evacuation guidance using a UAV," U.S. Patent Application no. 201715596783.

[27] L. Kolobe, et al., "Systematic literature survey: applications of LoRa communication," International Journal of Electrical and Computer Engineering (IJECE), vol. 10, no. 3, pp. 3176-3183, 2020.

[28] S. Hosseinzadeh, "Empirical propagation performance evaluation of LoRa for indoor environment," IEEE 15th International Conference on Industrial Informatics (INDIN), pp. 26-31, 2017.

[29] X. H. Xie, et al., "An Intelligent Smoke Detector System Based on LoRa and Indoor Positioning," DEStech Transactions on Computer Science and Engineering, 2018.

[30] J. Huixian and Z. Shaoping, "Design of intelligent fire-fighting system of a big public building emergency evacuation navigation system for mobile terminal," 13th International Conference on Computer Science and Education(ICCSE 2018), pp. 90-95, 2018.

[31] J. Seebamrungsat, et al., "Fire Detection in the Buildings Using Image Processing," Third ICT International Student Project Conference (ICT-ISPC), pp. 95-98, 2014.

[32] K. Xie, et al., "Internet of Things-based intelligent evacuation protocol in libraries," Library Hi Tech, vol. 38, no. 1, pp. 145-163, 2019.

[33] S. Fong, "Internet of Breath (IoB): Integrative Indoor Gas Sensor Applications for Emergency Control and Occupancy Detection," First International Conference on Real Time Intelligent Systems, pp. 342-359, 2017.

[34] M. S. B. Bahrudin, et al., "Development of Fire alarm system using Raspberry Pi and Arduino Uno," 2013 International Conference on Electrical Electronics and System Engineering(ICEESE 2013), pp. 43-48, 2013.

[35] J. Ma, "Research of Building Evacuation Path to Guide Based on BIM," 29th Chinese Control and Decision Conference (CCDC), pp. 1814-1818, 2017.

[36] Z.C. Zou, et al., "Intelligent Space for Building Fire Detection and Evacuation Decision Support," Proceedings of the 2015 International Conference on Electrical, Automation and Mechanical Engineering, pp. 365-368, 2015.

[37] Y. Bo, et al., "A GIS-Based Simulation for Occupant Evacuation in an Amusement Building," 2nd International Asia Conference on Informatics in Control, Automation and Robotics, pp. 274-277, 2010. 
[38] F. Tingyong, et al., "Study of building fire evacuation based on continuous model of FDS\&EVAC," International Conference on Computer Distributed Control and Intelligent Environmental Monitoring (CDCIEM 2011), pp. 1331-1334, 2011.

[39] D. Lee, et al.,"Environment Adaptive Emergency Evacuation Route GUIDE through Digital Signage Systems,"International Journal of Advanced Culture Technology (IJACT), vol. 5, no. 1, pp. 90-97, 2017.

[40] S. Spinsante, "A LoRa enabled building automation architecture based on MQTT," AEIT International Annual Conference, pp. 1-5, 2017.

[41] Y. Chen, et al., "Design of Security Alarm System Based on LoRa Technology," International Conference on Geoinformatics in Sustainable Ecosystem and Society, pp. 280-288, 2018.

[42] N. E. Chung, et al., "An effectiveness study of an intelligent emergency evacuation system using field verification techniques," 2017 6th International Conferenceon Future Generation Communication Technologies (FGCT 2017), pp. 78-83, 2017.

[43] J. S. Chou, et al., "Optimal path planning in real-time for dynamic building fire rescue operations using wireless sensors and visual guidance," Automation in Construction, vol. 99, pp. 1-17, 2019.

[44] A. Gaur, et al., "Fire Sensing Technologies: A Review," IEEE Sensors Journal, vol. 19, no. 9, pp. 3191-3202, 2019.

[45] S. Majumder, et al., "Smart apparatus for fire evacuation — an IoT based fire emergency monitoring and evacuation system," 2017 IEEE MIT Undergraduate Research Technology Conference (URTC), pp. 1-4, 2017.

[46] N. Al-Nabhan, et al., "A Hybrid IoT-based Approach for Emergency Evacuation," Computer Networks, vol. 155, pp. 87-97, 2019.

[47] A. Johnson, et al., "Adaptive Kinetic Architecture and Collective Behavior: A Dynamic Analysis for Emergency Evacuation," Buildings, vol. 9, no. 2, pp. 44-55, 2019.

[48] H. Chu, et al., "Emergency Evacuation Simulation and Management Optimization in Urban Residential Communities," Sustainability, vol. 11, no. 3, pp. 795-819, 2019.

[49] K. M. Yu, et al., "Construct an Intelligent Evacuation Guidance System with Open System Architecture," 2018 International Conference on Advanced Control, Automation and Artificial Intelligence (ACAAI 2018), pp. 214-217, 2018.

[50] C. E. Beller, et al., "Personalized emergency evacuation plan,” U.S. Patent Application No. 10/181,242.

\section{BIOGRAPHIES OF AUTHORS}
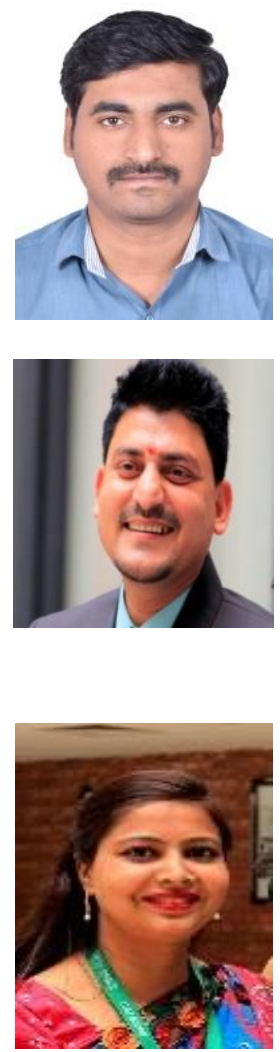

Gajanand S. Birajdaris a Research Scholar at Lovely Professional University, Punjab, India. He has completed his bachelor degree in Electronics \& Telecommunication Engineering from SPPU Pune and M. Tech in Embedded Systems from JNTU Hyderabad. His area of interest is IoT, Embedded Systems, Fire Safety, WSN, etc.
Dr. Rajesh Singhis currently working as a Professor with more than fifteen years of experience in academics. He has been awarded as a gold medalist in M.Tech and honors in his B.E. His area of expertise includes embedded systems, robotics, wireless sensor networks, and the Internet of Things. He has organized and conducted several workshops, summer internships, and expert lectures for students as well as faculty. He has 27 patents in his account. He has published around hundred research papers in refereed journals/conferences. Under his mentorship students have participated in national/international competitions including Texas competition in Delhi and Laureate award of excellence in robotics engineering in Spain. Twice in the last four years, he has been awarded a "certificate of appreciation".

Dr. Anita Gehlothas more than twelve years of experience in academics. She has twenty-four patents in her account. She has published more than fifty research papers in refereed journals and conferences. She has organized several workshops, summer internships, and expert lectures for students. She has been awarded a "certificate of appreciation" from the University of Petroleum and Energy Studies for exemplary work. She has published fifteen books in the area of Embedded Systems and Internet of Things with reputed publishers like CRC/Taylor \& Francis, Narosa, GBS, IRP, NIPA, River Publishers, Bentham Science, and RI publication. She is an editor of a special issue published by the AISC book series, Springer with the title "Intelligent Communication, Control, and Devices-2018". 


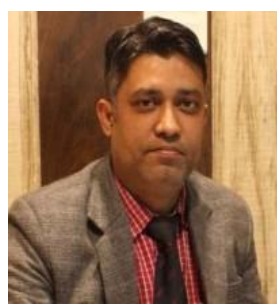

Dr. Amit Kumar Thakur is currently associated with Lovely Professional University as an Associate Professor with more than seventeen years of experience in academics and research. His area of expertise includes Renewable energy technologies, Thermal energy, Robotics, and the Internet of Things. He has organized and conducted several workshops, summer internships, and expert lectures for students as well as faculty. He has published around Twenty four research papers in refereed journals/conferences. He is the Life Member of The Indian Society for Technical Education (ISTE), a faculty member of the Society of Automotive Engineers (SAE), life member of The Aeronautical Society of India (AMeASI). He is the editorial board member and reviewer of various reputed journals. He was the Research sub-coordinator for ADRDE, DRDO in the project of design and development of the deceleration system for the Space capsule recovery experiment (SRE). He has five patents to his name. He is the editor of two books, one from CRC press by Taylor \& Francis and one from Nova Science Publishers. 